\title{
Nuevas herramientas para viejos problemas: acoso y ciberacoso a través de un análisis de sentencias
}

\author{
Susana Blanco Fernández \\ Doctora en Psicología y psicóloga forense en el Gabinete de Psicología Recursos \\ susanablancofernandez@hotmail.com \\ Carmen González Pais \\ Psicóloga forense en el Gabinete de Psicología Recursos \\ recursospsicologia@gmail.com \\ Judith Velasco Rodríguez \\ Investigadora en el Departamento de Psicología de la Universidad de Córdoba \\ judith.velasco@outlook.es
}

Este trabajo ha sido seleccionado para su publicación por: doña Elena Faba de la Encarnación, doña Charo Fernández Aguirre, don Melchor Gómez García, doña Laura Rayón Rumayor y don Javier Soriano Camino.

\section{Extracto}

El acoso escolar es una problemática social que afecta a niños, niñas y adolescentes de todo el mundo. Su elevada prevalencia, junto con la severidad de sus consecuencias, han hecho del bullying una cuestión prioritaria en lo que atañe a la salud física y psicoemocional de la infancia y adolescencia. Desde que comenzara a estudiarse en los años setenta, el interés por alcanzar su comprensión no ha cesado, lo que se ha traducido en un incremento del número de estudios, en el desarrollo de nuevas líneas de investigación y, en definitiva, en un ingente crecimiento del conocimiento sobre esta forma de violencia en todas sus modalidades (por ejemplo, ciberacoso), lo que ha permitido mejorar la asistencia a las víctimas. Sin embargo, cuando la gravedad del acoso excede las competencias de los centros educativos y requiere la intervención del sistema legal, se observan problemas conceptuales y metodológicos que tienen como consecuencia una respuesta deficitaria a las víctimas. El presente trabajo tiene por objeto conocer el modo en que el acoso escolar es conceptualizado y tratado en el ámbito jurídico a través de un análisis de las sentencias dictadas sobre el mismo.

Palabras clave: ciberacoso; daño psicológico; nuevas tecnologías; educación; sentencias.

Fecha de entrada: 03-05-2019 / Fecha de aceptación: 15/07/2019

Cómo citar: Blanco Fernández, S., González Pais, C. y Velasco Rodríguez, J. (2020). Nuevas herramientas para viejos problemas: acoso y ciberacoso a través de un análisis de sentencias. Tecnología, Ciencia y Educación, 15, 51-80. 


\title{
New tools for old problems: bullying and cyberbullying through a court sentences analysis
}

\author{
Susana Blanco Fernández \\ Carmen González Pais
}

Judith Velasco Rodríguez

\begin{abstract}
Peer maltreatment is a social issue that affects youngsters worldwide. Its great prevalence and the harshness of its outcomes made bullying a critical topic when it comes to youth health. Since the 70s, the concern about this matter has not stopped growing, which has led to the increase of studies, the development of new research lines, and, consequently, a finer knowledge of this form of violence (or other modalities like cyberbullying) that allow better support to victims. However, when the severity of peer victimisation exceeds the competencies of schools and it requires the intervention of the legal system, certain conceptual and methodological issues have been observed. Hence, victims are receiving deficient attention. The present study addresses how bullying is conceptualised and treated in courts.
\end{abstract}

Keywords: cyberbullying; psychological damages; new technologies; education; court sentences.

Citation: Blanco Fernández, S., González Pais, C. y Velasco Rodríguez, J. (2020). New tools for old problems: bullying and cyberbullying through a court sentences analysis. Tecnología, Ciencia y Educación, 15, 51-80. 


\section{Sumario}

1. El acoso escolar: definición y características

1.1. Clasificación de las conductas de acoso

1.2. Roles implicados

1.3. Diagnóstico diferencial

1.4. Consecuencias derivadas del acoso escolar

2. Las nuevas tecnologías y la adolescencia: la necesidad de educación

2.1. Riesgos del acceso a internet sin precauciones

3. Estudio empírico

3.1. Objetivo

3.2. Método

3.2.1. Participantes

3.2.2. Procedimiento

3.3. Resultados y discusión

3.4. Otras cuestiones relacionadas con los hallazgos en las sentencias

3.5. Conclusiones

3.5.1. Respecto al acoso escolar

3.5.2. Respecto a la utilización de las nuevas tecnologías en el acoso escolar

3.5.3. Respecto al uso de las nuevas tecnologías por parte de la población más joven

4. Señales de alarma y pautas de actuación para los progenitores y docentes ante el bullying y/o el ciberacoso

4.1. Señales de alarma

4.2. Pautas de actuación

Referencias bibliográficas 


\section{El acoso escolar: definición y características}

El acoso escolar es una forma de violencia que tiene lugar en el ámbito educativo y que afecta aproximadamente al $5 \%$ del alumnado de todo el mundo. Los primeros esfuerzos por estudiarlo de modo operativo datan de los años setenta, de la mano de investigadores como Olweus (1998), quien lo define en los siguientes términos:

\author{
Un alumno es agredido o se \\ convierte en víctima cuando está \\ expuesto, de forma repetida y \\ durante un tiempo, a acciones \\ negativas que lleva a cabo otro \\ alumno o varios de ellos
}

Un alumno es agredido o se convierte en víctima cuando está expuesto, de forma repetida y durante un tiempo, a acciones negativas que lleva a cabo otro alumno o varios de ellos (p. 25).

Dichas acciones negativas son descritas tal y como sigue (Olweus, 1998):

Se pueden cometer acciones negativas de palabra, por ejemplo, con amenazas y burlas, tomar el pelo o poner motes. Comete una acción negativa quien golpea, empuja, da una patada, pellizca o impide el paso a otro -mediante el contacto físico-. También es posible llevar a cabo acciones negativas sin el uso de la palabra y sin el contacto físico, por ejemplo, mediante muecas, gestos obscenos, excluyendo de un grupo a alguien adrede, o negándose a cumplir los deseos de otra persona (p. 25).

Tomando en consideración esta definición, Olweus (1998) plantea que en toda situación de acoso deben aparecer tres criterios:

- Intencionalidad. Según la naturaleza de la conducta violenta, esta puede ser reactiva, cuando se manifiesta como una respuesta emocional intensa tras un evento catalizador (por ejemplo, provocación), y proactiva, cuando se produce una respuesta cognitiva deliberada dirigida a la consecución de un objetivo específico. El acoso escolar sería un ejemplo de esta última. Esta cuestión es fundamental debido a que la violencia entre iguales ha sido frecuentemente clasificada como 
un subtipo de agresión, lo que ha llevado a la errada asunción de que todas las conductas violentas que suceden en el ámbito educativo constituyen acoso. La sobre inclusión de comportamientos de violencia escolar en las evaluaciones se ha concretado en la aparición de errores de medida que influyen en aspectos tan relevantes como la estimación de su prevalencia o el desarrollo de estrategias de intervención efectivas (Rigby, 2002).

- Desequilibrio de poder. Debe existir un desequilibrio entre las partes (Ovejero, 2013; Stein, Dukes y Warren, 2007), el cual no se limita a la fuerza física, sino que puede resultar de diversas situaciones de ventaja social (por ejemplo, desempeñar un rol dominante en el grupo, contar con mayor estatus social o mayor número de seguidores). La relación de poder asimétrica implica que la víctima tiene dificultad para defenderse.

- Duración y repetición. Las conductas de acoso han de producirse de manera frecuente y prolongarse a lo largo de un periodo de tiempo. Pese a que no se ha consensuado la duración de este, se suele considerar un periodo de entre dos y tres meses. Con respecto a la repetición, se propone una frecuencia de «dos o tres veces al mes» o «aproximadamente una vez a la semana» (Olweus y Limber, 2010, p. 20). El criterio de cronicidad reviste importancia de cara a la evaluación del bullying, ya que es uno de los criterios fundamentales para distinguir el acoso de otras manifestaciones de violencia en el ámbito escolar (por ejemplo, ser peleas, conflictos entre iguales, etc.). No obstante, de facto, existen ejemplos en la jurisprudencia española en los que no se ha considerado imprescindible la reiteración de las conductas, siendo considerado como acoso un acto de intensidad suficiente que atente contra la integridad moral de la persona (Sentencia del Tribunal Supremo [STS] $819 / 2002$, de 8 de mayo).

\subsection{Clasificación de las conductas de acoso}

El acoso escolar se puede categorizar según el tipo de violencia que se ejerza, encontrándose formas de violencia física, verbal, psicológica y relacional (Consellería de Cultura, Educación e Ordenación Universitaria, 2015; Megías y Rodríguez, 2014). La mayoría de las conductas de maltrato se caracterizan por la combinación de diferentes formas de violencia, por lo que se destaca el papel transversal de la violencia psicológica, común a todas las formas de acoso entre iguales (Avilés, 2006; Björkqvist, 2001). Con esto en mente, se procede a describir cada una de las formas de violencia:

- Violencia física. Pretende generar un perjuicio físico en la víctima de forma directa (por ejemplo, puñetazos, patadas, empujones, etc.) mediante amenazas con armas, ataques a la propiedad (por ejemplo, romper libros, esconder pertenencias, etc.) o a través de la sustracción de pertenencias personales. La literatura advierte de 
que este tipo de violencia es más frecuente entre los chicos (Defensor del Pueblo, 2007), especialmente en los últimos años de primaria y los primeros de secundaria (9-14 años), disminuyendo a medida que se incrementa el nivel educativo. La violencia física es la manifestación más reconocida del bullying debido a la visibilidad de sus consecuencias y, por ende, a la facilidad para identificarla. A pesar de esto, no se trata de la forma de abuso más frecuente. En nuestro país, los informes señalan que entre el 4 y el $6 \%$ de las víctimas ha experimentado violencia física directa (Defensor del Pueblo, 2007; Díaz-Aguado, Arias y Babarro, 2010; Dobarro, 2011; Sastre, 2016).

- Violencia verbal. Consiste en usar el lenguaje (insultos, motes desagradables, agresividad verbal, burlas, etc.) para provocar daños en la víctima. Es el tipo de acoso más común en las

El acoso verbal exige una atención temprana porque puede ser un indicio de la existencia de otras formas de maltrato aulas españolas. Aproximadamente, el $30 \%$ del alumnado refiere haber sido víctima de agresiones verbales, frente al $4 \%$ que describe violencia física. Con todo, esta forma de violencia ha sido habitualmente descuidada debido a su normalización y aceptación social, subestimando su gravedad. El acoso verbal exige una atención temprana por dos motivos fundamentales: porque genera un impacto psicoemocional negativo en las víctimas, especialmente perceptible a largo plazo (DeLay et al., 2016), y porque puede ser un indicio de la existencia de otras formas de maltrato.

- Violencia psicológica. Se caracteriza por producir un perjuicio en el bienestar psicológico de la víctima mediante amenazas, burlas o humillaciones (RodicioGarcía e Iglesias-Cortizas, 2011). La violencia psicológica ha suscitado cierta polémica debido a que todas las conductas de acoso escolar generan malestar psicológico en la víctima, incluso en aquellas agresiones de naturaleza física (golpes, empujones, robos, etc.), cuyo fin último no es ocasionar daño físico, sino infundir un temor suficiente en la víctima como para que se someta a la voluntad del agresor.

- Violencia relacional. Su objetivo es dañar a la víctima a través del menoscabo de sus relaciones interpersonales mediante formas de acoso indirecto (por ejemplo, difusión de rumores, aislamiento, manipulación, etc.).

Otras clasificaciones posibles son:

- Según si es acoso explícito o implícito:

- Acoso directo: si existe confrontación entre víctima y victimario (por ejemplo, agresiones físicas y verbales). 
- Acoso indirecto: cuando la agresión se produce de manera encubierta (Olweus, 1983).

- Según el motivo del acoso:

- Acoso por razón de raza o etnia.

- Hacia alumnado con necesidades educativas especiales.

- Acoso por razón de identidad de género y de orientación sexual.

Si bien todas las formas de acoso descritas comparten una serie de características centrales, establecer taxonomías diferenciales es fundamental para programar intervenciones efectivas adecuadas a las necesidades específicas y particularidades de las víctimas.

\subsection{Roles implicados}

La investigación en acoso se ha centrado, tradicionalmente, en la díada acosador-acosado. Sin embargo, el conocimiento del que disponemos en la actualidad ha puesto de manifiesto la existencia de roles cuya implicación es más decisiva en el origen y mantenimiento de la conducta violenta que la propia actuación del acosador, como es el caso del alumnado observador. A continuación, se describen brevemente cada uno de los roles y sus principales características:

- Víctima. Conceptualmente, la víctima se define como la persona sobre la cual se ejerce el maltrato (Roa et al., 2012). Este grupo es el más heterogéneo de los tres roles que componen la dinámica de acoso, lo que se traduce en que cualquier estudiante puede ser potencialmente víctima de maltrato por parte del grupo de iguales (Martos y Del Rey, 2013). Dicho esto, cabe señalar que, aunque no existe un arquetipo de víctima, la investigación ha identificado ciertas características que el alumnado acosador emplea para fundamentar sus agresiones y maximizar su probabilidad de éxito, buscando, de este modo, estudiantes vulnerables que presentan una valoración negativa del grupo de iguales (Reijntjes et al., 2016), la falta de relaciones interpersonales de apoyo (Brewer y Kerslake, 2015; Juvonen y Galván, 2008) o el uso de estrategias de afrontamiento desadaptativas (por ejemplo, tratan de solucionar la situación por sí mismos).

- Persona agresora. De nuevo, a pesar de que se trata de un grupo muy heterogéneo, se observan ciertas características comunes. De modo general, son varones, agresivos, impulsivos y dominantes, que presentan baja tolerancia a la frustración. Con frecuencia, muestran conductas desafiantes y actitudes negativas hacia la escuela y el profesorado; ostentan mayor poder que la víctima (físico, 
amistades, ingenio, popularidad, etc.); mantienen actitudes positivas hacia la violencia; y consideran que su uso les reporta beneficios, tales como amistades, popularidad o bienes materiales, es decir, presentan una concepción instrumental de la violencia (Velasco et al., 2014).

- Espectadores. Los estudios relacionales señalan que en un episodio de acoso hay un promedio de cuatro personas espectadoras presentes, las cuales pasan el $54 \%$ del tiempo observando los hechos sin intervenir (Howard, Landau y Pryor, 2014). No tomar parte por la víctima implica una

Las personas acosadoras no actúan si no hay testigos presentes, sino que reservan las agresiones para momentos y lugares concretos en los que haya público con el objetivo de obtener poder social aceptación tácita de la situación de acoso que refuerza la conducta de la persona que ejerce la agresión y que contribuye a perpetuar la victimización (Salmivalli, Sainio y Hodges, 2013). Diversos estudios han destacado la importancia del papel del público para acabar con el bullying debido a su capacidad para alterar la conducta de las personas que agreden (Kärnä, Voeten, Poskiparta y Salmivalli, 2010; Zych, Ortega y Del Rey, 2015). Se ha observado que las personas acosadoras no actúan si no hay testigos presentes, sino que reservan las agresiones para momentos y lugares concretos en los que haya público con el objetivo de obtener poder social (Salmivalli, 2014). Los estudios de observación parecen apoyar esta hipótesis, al haber detectado que el acoso está más presente y que existen episodios de mayor gravedad en los centros en los que el auditorio refuerza al que ejerce el acoso (Kärnä et al., 2011; Thornberg, 2012), y que se extingue cuando las personas que observan lo condenan o censuran (Thornberg y Jungert, 2013).

\subsection{Diagnóstico diferencial}

Una inadecuada evaluación del acoso se asocia a diferentes consecuencias negativas (por ejemplo, errores de medida, errores en el planteamiento de intervenciones, etc.). Una de las causas que más dificultades genera es la ausencia de una definición operativa consensuada, puesto que lleva a que se incluyan en los cuestionarios diversas conductas violentas que acaecen en el entorno educativo y que no constituyen acoso. Empleando los criterios propuestos por Olweus (1983) es posible hacer una distinción entre situaciones agresivas que se producen en el marco relacional normativo de la infancia y la adolescencia y el bullying. De modo general, los elementos más frecuentemente confundidos con el acoso escolar son:

- Juego violento. El juego es un mecanismo adaptativo que permite el desarrollo de habilidades cognitivas, sociales y comunicativas (Pellegrini y Smith, 1998), así como 
estrategias de aprendizaje social y mecanismos de control y de expresión de la ira en la infancia. El juego violento presenta ciertas características que permiten diferenciarlo del acoso (Smith, Smees y Pellegrini, 2004), y es que, aunque puede producirse de manera regular y continuada (temporalidad), no satisfaría el criterio de desequilibrio de poder, ya que todas las personas implicadas se encontrarían al mismo nivel.

- Agresiones y conflictos. La convivencia implica que en ocasiones se produzcan conflictos entre las personas. Habitualmente se trata de hechos restringidos a situaciones específicas en los que existe un acontecimiento que enfrenta a las dos partes. El hecho catalizador puede ser real o percibido, pero, en ambos casos, amenaza los intereses de una de las partes. Las acciones que se producen en este contexto tienen por objeto la consecución de los recursos disputados o la obtención de algún tipo de beneficio, con lo que la gente implicada podría mostrar conductas agresivas e incluso violentas. En el caso de los conflictos puntuales, no se cumplen los criterios de temporalidad ni de desequilibrio de poder.

- Agresividad. Hay niños y niñas que actúan de manera agresiva con sus iguales. Su comportamiento puede estar motivado por factores como la obtención de dominio sobre el grupo de iguales, la imposición de su propio criterio, la oposición a la autoridad o características de personalidad. Aunque algunas personas acosadoras son definidas como violentas, no se ha observado una correlación entre la personalidad violenta y el bullying. La diferencia entre ambas casuísticas radica en que la infancia violenta actúa de manera agresiva indiscriminadamente, mientras que, en el acoso, la persona que agrede focaliza su ira sobre un objetivo determinado.

- Clima de violencia escolar. La violencia escolar es definida como cualquier tipo de acto violento que se produce en los centros escolares, independientemente de si va dirigida al alumnado, al profesorado o a las instalaciones del centro (D’Angelo y Fernández, 2011). Un clima escolar de violencia perjudica el proceso de aprendizaje y las relaciones sociales dentro de las aulas, generando efectos como la normalización de la violencia (Blaya, Debarbieux, Del Rey y Ortega, 2006). Aunque en los centros en los que reina un clima violento pueden darse agresiones hacia camaradas, estas son el resultado de las interacciones negativas generalizadas que se producen en el seno de la comunidad educativa. En el acoso escolar las agresiones van dirigidas a una víctima concreta, no siendo frecuente que se actúe de forma violenta hacia otras personas en el centro.

\subsection{Consecuencias derivadas del acoso escolar}

La conceptualización del acoso pone de relieve las implicaciones psicológicas, emocionales y sociales que pueden derivarse del mismo. Sin embargo, es importante incidir en el hecho de que las consecuencias negativas de la exposición al acoso no se circunscriben a 
la víctima, como cabría suponer. Contrariamente, la literatura ha puesto de manifiesto que todas las personas implicadas en el maltrato entre iguales experimentan malestar psicoemocional a corto y largo plazo, incrementando la probabilidad de que aparezcan trastornos psicológicos y comportamentales. En quien acosa se ha observado mayor prevalencia de trastornos psicopatológicos, como ansiedad, depresión y dependencia a sustancias, así como una mayor implicación en conductas delictivas y otras formas de maltrato como la violencia de género o el acoso laboral. Por su parte, en el alumnado espectador se han identificado distorsiones cognitivas relacionadas con la percepción de la justicia social y deficiencias en el desarrollo moral.

Con todo, en este trabajo nos centraremos en las consecuencias que el acoso produce en las víctimas. Así, en lo que respecta a esta perspectiva, el acoso se asocia con un amplio espectro de problemas físicos, psicológicos y relacionales (Hoffman, Phillips, Daigle y Turner, 2017) que van desde el menoscabo del funcionamiento psicológico deseable hasta trastornos psicopatológicos en la edad adulta (Evans-Lacko et al., 2017). Así, factores como el tipo de acoso, la intensidad, la duración y la persistencia configuran la entidad de los desajustes que las víctimas experimentan a lo largo de la vida. La adolescencia es un periodo de cambios, una etapa en la que se desarrollan aspectos nucleares de la personalidad en busca de una identidad propia. Consecuentemente, los efectos perniciosos del maltrato no se limitan al momento en el que se produce la victimización ni se restringen al ámbito escolar, sino que tienen un impacto negativo sobre todas las esferas de la vida de las víctimas, afectando a su salud mental, relaciones interpersonales y desempeño global, y pudiendo prolongarse estos efectos tras el cese de la violencia. De facto, Evans-Lacko et al. (2017) encontraron que las víctimas de acoso escolar hacen un mayor uso de los servicios de salud mental hasta cinco décadas después del fin del acoso.

El rechazo y el aislamiento al que se ven sometidas las víctimas producen diversos sentimientos negativos. Como se describió anteriormente, las víctimas no suelen contar con amistades en el centro (Reijntjes, Kamphuis, Prinzie y Telch, 2010) y esto les provoca inadaptación, ansiedad y estrés, no solo por los efectos inherentes al aislamiento, sino también porque, además, la amistad es un elemento crucial en el desarrollo cognitivo y psicosocial (Fuertes, Martínez y Hernández, 2001). Siguiendo a Berger (2016), «los adolescentes se apoyan mucho en sus pares para que los ayuden a recorrer los cambios físicos en la pubertad, los desafíos intelectuales de la secundaria y los cambios sociales de la transición de la infancia a la adolescencia» (p. 482). Durante este periodo evolutivo se inicia un «proceso de individuación y autonomía de los progenitores y, en consecuencia, los amigos pasan a ser valorados como la principal fuente de influencia en detrimento de la vida familiar» (Martínez, 
2014, p. 2). El grupo de iguales proporciona un espacio en el que desarrollarse en un marco de interacción social a partir del cual la juventud construye su identidad, personalidad (Berger, 2016) y autoestima (Griffin y Gross, 2004). La importancia de la relación con el grupo de iguales se pone de relieve en el valor asignado durante esta etapa a la popularidad. Este concepto, relacionado con el número de amistades, determina el estatus de la jerarquía grupal durante la adolescencia; por extensión, su valía personal autopercibida (Berger, 2016). En este sentido, las víctimas de acoso carecen de un importante elemento de apoyo en su proceso de socialización.

De la misma forma, las víctimas de acoso padecen con mayor frecuencia trastornos internalizantes como la ansiedad (AlBuhairan et al., 2017; Eastman et al., 2018; Gini, Card y Pozzoli, 2018). Se estima que entre el 6,4 y el 10,8\% de las víctimas presenta sintomatología ansiosa (Kaltiala-Heino, Rimpelä, Rantanen y Rimpelä, 2000) que puede manifestarse a través de fobias específicas, ataques de pánico (Antila et al., 2017) o trastorno de estrés postraumático (Nielsen, Tangen, Idsoe, Matthiesen y Magerøy, 2015). En lo que respecta a este último, las evidencias sobre su relación con el maltrato entre iguales son inconclusas, fundamentalmente por la dificultad que supone que las situaciones de acoso satisfagan el criterio A, habiéndose recomendado que el diagnóstico se subsuma en el trastorno adaptativo.

Aunque el estudio de las consecuencias del bullying se ha centrado en los efectos del maltrato sobre la salud psicoemocional, un número creciente de investigaciones ha mostrado que el acoso también incide sobre la salud física de las víctimas (Baldry, 2004; Slee, 1995). Por otro lado, la investigación ha evidenciado que la exposición prolongada a situaciones ansiógenas (por ejemplo, malos tratos, abusos sexuales, abandono, etc.) puede producir alteraciones neurobioquímicas y neuroestructurales que se relacionan con un in-
La exposición prolongada a situaciones ansiógenas puede producir alteraciones neurobioquímicas y neuroestructurales que se relacionan con un incremento de la vulnerabilidad a experimentar estados psicopatológicos cremento de la vulnerabilidad a experimentar estados psicopatológicos (Kim-Cohen et al., 2006). Dado que el acoso escolar es una situación de violencia física y psicológica que se prolonga a lo largo del tiempo, desde la investigación se ha planteado la necesidad de examinar si es posible que genere efectos similares a los descritos en otras formas de violencia.

\section{Las nuevas tecnologías y la adolescencia: la necesidad de educación}

La violencia a través de las nuevas tecnologías se muestra como un fenómeno propio del siglo XXI, estrechamente vinculado con la difusión y el uso masivo de las tecnologías 
de la información y la comunicación (TIC). Es la población menor, y, especialmente, adolescente, la que, estando permanentemente conectada, hace del espacio virtual su nuevo foro de socialización. Sin embargo, dado que los progenitores no son nativos digitales, en muchas ocasiones presentan fuertes déficits en cuanto a su capacidad para poder educar y prevenir al sector infantil sobre los peligros que albergan las nuevas tecnologías (por ejemplo, sexting, grooming, etc.).

En otras ocasiones, la violencia surge del anonimato o de las herramientas que proporcionan las nuevas tecnologías, como puede ser el ciberacoso. Es necesario comprender que las personas que han nacido en la era digital usan la mensajería instantánea o las redes sociales como un modo natural de interactuar y comunicarse. Los datos indican que el $90 \%$ de la población más joven la utiliza a diario (Livingstone, Haddon, Görzig y Ólafsson, 2011), siendo el control parental la principal barrera en su uso-abuso. Sin embargo, a pesar de las advertencias de los expertos sobre la tenencia de estos dispositivos a edades tempranas, las investigaciones advierten de que, en el año 2014, el $30 \%$ de la población menor de 10 años ya disponía de teléfono móvil, incrementándose hasta el $70 \%$ a los 12 años y al 83 \% a los 14 (Cánovas, García de Pablo, Oliaga San Atilano y Aboy-Ferrer, 2014), lo que dificulta el control que las familias pueden hacer sobre un uso adecuado. Además, diversos estudios señalan que un 37,3\% de jóvenes entre los 12 y los 18 años dedica entre una y dos horas diarias a internet, y un 21,3\%, más de tres (Ochaita, Espinosa y Gutiérrez, 2011). Y aunque el uso de las TIC tiene un componente positivo evidente, también alberga un lado negativo por falta de control e información, influyendo en las habilidades sociales y cognitivas de la infancia de modo implacable, ya que facilitan la inmediatez y la desinhibición de la comunicación. Por otra parte, no debemos olvidar que el autoconcepto de menores y adolescentes, siempre vinculado a la opinión de su grupo de referencia, se ve afectado en este mundo digital por los likes y la valoración que reciben en las redes sociales.

Mientras que, para las generaciones anteriores, las TIC adoptan un valor instrumental, para la población nativa digital se convierten en una parte intrínseca, entendiéndolas y viviéndolas como una extensión de su vida cotidiana, y en ella tiene lugar una gran parte de su socialización. En este contexto, el modo de interactuar a través de estos nuevos espacios virtuales ha dado lugar a una nueva forma de comunicarse basada en la inmediatez y el cortoplacismo (Benedicto, Echaves, Jurado, Ramos y Tejerina, 2017). El problema surge cuando la responsabilidad se difumina y no se tienen en consideración las posibles consecuencias de los actos realizados a través del mundo virtual. La desinhibición de la comunicación puede resultar favorable para aquellas personas con dificultades para relacionarse, porque reforzaría la creación de apoyo y el desarrollo de sentido de comunidad (Calmaestra, Ortega y Mora-Merchán, 2008; Kowalski, Limber y Agatston, 2010). Sin embargo, los contenidos de la red no son inocuos, y el elevado porcentaje de dispositivos móviles que facilita el acceso, 
la cantidad de horas que permanecen conectados, la sensación de invulnerabilidad y la baja percepción de horas de consumo diarias generan un caldo de cultivo que les hace estar expuestos a riesgos de los que en ocasiones ni siquiera son conscientes.

\section{El problema surge cuando la responsabilidad se difumina y no se tienen en consideración las posibles consecuencias de los actos realizados a través del mundo virtual}

\subsection{Riesgos del acceso a internet sin precauciones}

El consumo excesivo de tecnología sin una adecuada supervisión y sin tomar unas mínimas precauciones puede dar lugar a múltiples situaciones problemáticas. Una de ellas es la «nomofobia», o el miedo irracional a salir de casa sin el móvil, a quedarnos sin batería, etc. Aunque no existe un consenso en la literatura científica sobre esta nueva adicción sin drogas, está claro que, cada vez más, la juventud presenta consecuencias negativas derivadas de su abuso. Además, la normalización de su utilización casi permanente dificulta la percepción de los posibles riesgos (Soto, De Miguel y Díaz, 2018).

Otras investigaciones también destacan que las redes sociales son un factor de riesgo para el desarrollo de "problemas de autoestima» (Castilla y Vicente, 2018). En este sentido, se ha visto que el estereotipo de belleza que promueven las redes, así como la publicidad en las mismas, puede llegar a generar desórdenes alimenticios y baja autoestima. Aunque se han encontrado diferencias entre hombres y mujeres, ambos se ven afectados por esta problemática al intentar cumplir con los cánones
Otro fenómeno íntimamente relacionado con la autoestima y con el modo de conseguir puntos, likes o popularidad en las redes sociales son los crecientes retos virales, que pueden poner en serio riesgo la vida de los menores y adolescentes «impuestos» para ellos y ellas. Otro fenómeno íntimamente relacionado con la autoestima y con el modo de conseguir puntos, likes o popularidad en las redes sociales son los crecientes retos virales, que pueden poner en serio riesgo la vida de los menores y adolescentes (por ejemplo, la Ballena Azul [reto con 15 pruebas de graduación creciente que implican desde el visionado de películas de terror, a permanecer mucho tiempo sin dormir o a autolesionarse dibujando una ballena en el cuerpo, y que culmina con el salto al vacío desde un edificio]; la moda de realizar selfis-skywalking en lugares de difícil acceso o peligrosos, etc.). Es decir, existe un elevado porcentaje de menores que deciden hacer cualquier cosa por la necesidad de agradar a los demás y obtener un feedback positivo, para no ser menos que los demás, para ganar simpatizantes, etc.

En otro grupo podemos incluir el peligro de acceder a "contenidos inapropiados», bien por edad, bien por favorecer o apoyar actitudes y actividades no saludables o incí- 
vicas. No olvidemos que en la red circulan todo tipo de vídeos y existen todo tipo de comunidades. Desde las que apoyan diversas clases de violencia, a las que promueven la anorexia, etc. Por otra parte, en la mayoría de las ocasiones las familias no saben a qué dedica el tiempo su progenie cuando está conectada, a qué videojuegos accede, qué información busca, etc.

Como ya hemos comentado, debido al anonimato que proporciona la red y a la no identificación fehaciente del interlocutor con el que creemos estar hablado o compartiendo información, existen fenómenos como el denominado «grooming», que está castigado en el artículo 183 ter del Código Penal:

1. El que a través de internet, del teléfono o de cualquier otra TIC contacte con un menor de 16 años y proponga concertar un encuentro con el mismo a fin de cometer cualquiera de los delitos descritos en los artículos 183 y 189, siempre que tal propuesta se acompañe de actos materiales encaminados al acercamiento [...].

2. El que a través de internet, del teléfono o de cualquier otra TIC contacte con un menor de 16 años y realice actos dirigidos a embaucarle para que le facilite material pornográfico o le muestre imágenes pornográficas en las que se represente o aparezca un menor [...].

Relacionado con el contenido sexual, encontramos también el sexting, que consiste en el envío de material de naturaleza sexual. Aunque en un principio la población infantil y juvenil pueda acceder a realizar dichas prácticas voluntariamente, no son infrecuentes las situaciones en que, a corto o medio plazo, esto genera consecuencias muy graves, bien por la difusión a terceros no autorizada, bien por la amenaza de realizar tal transmisión si no se accede a determinada petición. Además de los nefastos resultados evidentes de modo inmediato, este acto se hace extensivo en pocos segundos, pasando a tener una audiencia universal, perdiendo totalmente el control sobre la información compartida.

Además de los riesgos genéricos de las TIC a los que hemos aludido, el mal uso de las mismas se ha extendido a las situaciones de acoso, dando lugar a una modalidad específica del mismo conocida como «ciberacoso». De este modo, el maltrato del grupo de pares puede incluir los contenidos tradicionales (amenazas, burlas o insultos), pero difundidos a través del medio virtual; o adquirir nuevas versiones o modalidades, como son la suplantación de identidad o la denominada happyslapping (grabar una paliza con la intención de difundirla posteriormente). En estos casos, se persigue el mismo objetivo que con el bullying, pero la diferencia radica en que una sola acción, tal y como hemos visto, puede generar un daño irreparable, por su difusión, alcance e imposibilidad de subsanación posterior. Así, a diferencia del acoso tradicional, la víctima de ciberacoso se encuentra con que este no cesa al dejar de estar físicamente con el agresor, por lo que el maltrato se puede producir 24 horas al día/7 días a la semana. Además, se amplifica el número de personas destinatarias o testigos 
de las humillaciones de forma ilimitada (viralidad de la información) y se incrementa el impacto del daño, porque la información puede y suele permanecer en la red durante mucho tiempo o incluso para siempre. Por otra parte, el hecho de que la persona que ejerce el acoso no siempre sea identificable, al menos inicialmente, dificulta la detección y contribuye a que se lleve a cabo con mayor impunidad.

\section{La víctima de ciberacoso se}

encuentra con que este no cesa al dejar de estar físicamente con el agresor. Además, se amplifica el número de personas destinatarias o testigos de las humillaciones de forma ilimitada

\section{Estudio empírico}

Como hemos expuesto previamente, las nuevas tecnologías han traído importantísimas innovaciones y facilidades para la sociedad; y, concretamente, de cara a menores y adolescentes, han revolucionado los métodos docentes y el modo en que se relacionan con sus iguales. Sin embargo, existen riesgos que pasan desapercibidos para la infancia y la adolescencia, bien por la difusión de responsabilidad en el mundo virtual, bien por el sentimiento de invulnerabilidad, lo que lleva a que no se tomen las cautelas mínimas para garantizar una navegación e interacción segura en las redes.

En este estudio hemos decidido centrarnos en la comprobación del uso que se hace de las nuevas tecnologías en el fenómeno del acoso escolar.

\subsection{Objetivo}

Mediante el estudio de sentencias judiciales, queremos comprobar, por una parte, si existen estrategias o influencia de las nuevas tecnologías en el acoso escolar; y, por otra, a partir de los resultados, generar pautas dirigidas tanto a la infancia como a la adultez (bien familia o docentes) para prevenir, educar y concienciar de los riesgos de las TIC.

\subsection{Método}

\subsubsection{Participantes}

La unidad de estudio de esta investigación fueron 107 sentencias sobre acoso escolar de diversas regiones de España recogidas de las principales bases de datos jurídicas, a saber, Centro de Documentación Judicial (CENDOJ), Tirant Online y Aranzadi, acotadas desde el año 2005 al 2018. Todas ellas fueron examinadas individualmente y codificadas mediante las categorías que serán explicadas en el siguiente apartado. 


\subsubsection{Procedimiento}

Para la obtención de las sentencias, se introdujeron los siguientes descriptores booleanos: acoso escolar, bullying, maltrato entre iguales y victimización escolar, que proporcionaron un total de 465 sentencias. Sin embargo, la muestra se redujo a 107 sentencias, ya que era necesario que incluyeran información sobre diversas variables que la literatura señala como relevantes en este fenómeno.

Por una parte, se ha recopilado información sobre el proceso judicial: órgano (por ejemplo, juzgado de instrucción, Audiencia, tribunal superior de justicia, etc.), jurisdicción (civil, penal o contencioso-administrativo), delito solicitado e imputado (si es penal) o petición de la demanda; condena (medida y tiempo); indemnización (cuantía, medida de reparación del daño, etc.); pericial (por ejemplo, médica, psicológica, procedente de un equipo psicosocial, etc.); pruebas/ instrumentos administrados en la valoración del daño; tipo de secuelas/daño (por ejemplo, físico, psicológico, etc.); fallo (se aprecia acoso o no); y si se establece inacción del centro o no (es decir, si se concluye que el centro escolar se considera responsable o no por inacción in vigilando).

Por otra, se ha recabado información relativa a las características del acoso: edad y sexo de la víctima, edad y sexo de la población agresora, tipo de acoso (por ejemplo, psicológico, físico, relacional, etc.), número de personas agresoras (individual/grupal), cambio de centro educativo y medio por el que se ejerce el acoso (virtual, presencial o ambos).

\subsection{Resultados y discusión}

Las sentencias recogidas cubren el «periodo» que comprende desde el año 2005 al 2018. El $24 \%$ de las mismas procedía del CENDOJ, el $14 \%$ de Aranzadi y el $62 \%$ de Tirant Online. Respecto a la «jurisdicción», el $40 \%$ se referían a materia civil, el $51 \%$ a penal y el $9 \%$ al ámbito contencioso-administrativo; proviniendo la mayoría de las sentencias de la audiencia provincial (82\%), aunque también se aprecia representación del tribunal superior de justicia (6\%), del Tribunal Supremo (3\%), del juzgado de primera instancia (4\%), del contenciosoadministrativo (2\%), del juzgado de menores $(2 \%)$ y de la Audiencia Nacional (1\%). En cuanto a las "comunidades autónomas", la representación queda como sigue: Andalucía (13\%), Comunidad de Madrid (22\%), País Vasco (5\%), Cataluña (17\%), Comunitat Valenciana (12\%), Illes Balears (3\%), Canarias (2\%), Castilla y León (6\%), Galicia (6\%), CastillaLa Mancha (4\%), Cantabria (2\%), Ciudad Autónoma de Ceuta (1\%), Principado de Asturias (2\%), Extremadura (2\%) y Aragón (2\%).

En lo tocante a las «solicitudes iniciales», bien como objeto de la denuncia o de la demanda, a pesar de observar un amplio elenco de peticiones, la mayoría se concentran en delitos contra la libertad e integridad moral (34\%) o en solicitudes por vía civil de responsabilidad del centro de enseñanza culpa in vigilando (36\%). El resto de las solicitudes se 
distribuyen en lesiones (4\%), vejaciones (1\%), amenazas y coacciones (3\%), injurias (2\%), inducción al suicidio (2\%), maltrato (2\%), descubrimiento y revelación de secretos (2\%), y otros. Del análisis de los fallos de las sentencias extraemos que el delito finalmente imputado fue, mayoritariamente, coincidente con el solicitado al inicio del proceso.

Respecto a las variables directamente relacionadas con el acoso, encontramos que las "edades de las víctimas» oscilan entre los 8 y los 17 años, al igual que las de la población agresora, ya que en la gran mayoría de los casos se observa que el maltrato escolar proviene de colegas del mismo curso, bien siendo de la misma clase o, en todo caso, del mismo ciclo. A pesar del amplio rango de edad observado, el mayor número de víctimas se concentra en las edades que van de los 12 a los 14 años, coincidiendo con lo encontrado en la literatura. Cabe destacar, sin embargo, que se cuenta con 62 valores perdidos, ya que algunas sentencias no recogen la edad de las personas implicadas.

En relación a la variable «género», al analizar la categoría víctima, no encontramos diferencias significativas $\left(X^{2}=.009 ; p>.05\right)$, hallando 54 chicos y 53 chicas que habían denunciado acoso. Sin embargo, respecto a las personas que agreden, se aprecia la siguiente distribución estadísticamente significativa $\left(X^{2}=23,53\right.$; $p<.05)$ : 54 chicos, 34 chicas, 14 ocasiones
En lo tocante al colectivo agresor, una variable importante la encontramos al estudiar si actuaban en grupo o no, ya que el análisis muestra que el $73 \%$ de las agresiones se producen en un contexto grupal en las que el grupo de agresores estaba compuesto por chicos y chicas, y 5 valores perdidos. En lo tocante al colectivo agresor, una variable importante la encontramos al estudiar si actuaban en grupo o no, ya que el análisis muestra que el $73 \%$ de las agresiones se producen en un contexto grupal $\left(X^{2}=31,36\right.$; $p<.05)$, siendo esta una cuestión que entraña gran relevancia de cara a la implementación de programas de prevención y diversas formas de intervención.

En lo que atañe al «uso de las nuevas tecnologías» como medio para realizar los actos de acoso, encontramos que está presente en 31 ocasiones. No obstante, aunque a priori pueda parecer un porcentaje bajo, debemos tener en consideración dos cuestiones fundamentales. Primero, que el daño que provocan algunas de las prácticas incluidas en esta categoría puede entrañar, por sí mismo, un perjuicio irreparable por el elevado número de personas a las que llega, la velocidad a la que es compartido y la imposibilidad de deshacer o corregir el problema. $\mathrm{Y}$, en segundo lugar, en la mayoría de las sentencias en las que solo se discute si el centro escolar puso o no todos los medios necesarios para evitar el acoso, no se detallan los hechos propios constitutivos de bullying, sino que se analizan las actuaciones del centro, y, en consecuencia, existe una elevada pérdida de información respecto a qué tipo de estrategias de acoso se utilizaron en estos casos. Con estas cuestiones presentes, los datos respecto al uso de las nuevas tecnologías por las personas que ejercen el acoso muestran que hay diferencias significativas entre ambos géneros ( $P h i=.274$; $p<.05)$, siendo utilizadas en mayor medida por las chicas $(48 \%)$, por un $32 \%$ de los chi- 
cos y por un $19 \%$ integrado por un grupo mixto. Sin embargo, no se aprecian diferencias estadísticamente significativas en las víctimas $(P h i=-.150 ; p>.05)$, siendo padecido por las chicas en un $61,3 \%$ y por los chicos en un $38,7 \%$.

Las «estrategias de acoso a través de las nuevas tecnologías» más frecuentemente utilizadas son la grabación de las burlas o palizas para su posterior difusión; el envío de mensajes (tanto escritos como de audio) amenazantes mediante mensajería instantánea, colgándolos en Tuenti, Instagram, etc.; crear un grupo de WhatsApp en el que se introduce a la víctima para burlarse de ella, amenazarla, etc., incluyéndola una y otra vez si intenta abandonar el grupo; conseguir la clave de las redes sociales de la víctima y hacerse pasar por ella para insultar a sus amistades; subir fotos a internet, bien para mofarse de actividades que la víctima realiza, bien instantáneas modificadas para convertirla en objeto de burla; o, en ocasiones, incluso mientras se encuentran en el cuarto de baño; o llamadas de teléfono con número oculto.

Asimismo, se observa que en los fallos de las sentencias en las que se decretan órdenes de alejamiento ya no solo se hace referencia a la prohibición de aproximación o comunicación con la víctima, sino que en muchas de ellas se especifica que «no se podrá acercar al menor, ni comunicarse por móvil, Facebook, internet, redes sociales, etc.».

Al estudiar los «daños producidos», encontramos que el $67 \%$ de personas denunciantes o demandantes presentaban secuelas; el $28 \%$ no presentaba daños, apreciándose esta diferencia como significativa estadísticamente $\left(X^{2}=17,29 ; p<.05\right)$; y encontramos un $5 \%$ en el que no se concreta claramente. Atendiendo a la tipología de las secuelas, constatamos que el $17 \%$ son físicas, el $51 \%$ psicológicas, el $30 \%$ ambas, y obtenemos un $2 \%$ que refieren daños sin concretar.

Concretamente, sometiendo a estudio los «daños de tipo psicológico», se encontraron los siguientes diagnósticos: trastorno de estrés postraumático $(20 \%)$, trastorno adaptativo (16\%), depresión (2\%), ansiedad (21\%), somatizaciones (4\%), inadaptación social y baja autoestima (6\%), síndrome ansioso-depresivo (21\%), bajo rendimiento y tristeza (2\%), estrés (2\%), episodios autolesivos (2\%) y un $4 \%$ de secuelas psicológicas que no concretan diagnóstico. Asimismo, apreciamos una serie de síntomas que son tratados como secuela, pese a ser inherentes a multitud de síndromes inespecíficos, trastornos e incluso al propio proceso judicial. En consecuencia, constatamos que, en ocasiones, la relación causal puede no estar adecuadamente establecida.

En lo relativo al «estudio de las periciales» encontramos que el $54 \%$ de las sentencias sí presentaban algún tipo de pericial, en tanto que el $36 \%$ no hacía alusión alguna a ningún informe forense $\left(X^{2}=3,8 ; p=.051\right)$, con un $10 \%$ de valores perdidos, ya que en ocasiones no se concretaba claramente si se trataba de informes clínicos o forenses, dado que solo se hacía alusión a «el informe psicológico recogía que [...]». No obstante, dadas las grandes diferencias que existen entre periciales forenses e informes clínicos, estimamos necesario 
hacer una serie de consideraciones. La primera de ellas es que, en los informes forenses, existen dos cuestiones inexcusables: por una parte, el estudio de la simulación/manipulación de la sintomatología (American Psychiatric Association [APA], 2014) y, por otra, el establecimiento de la causalidad. Esto es, resulta necesario descartar que se estén inventando o exagerando las patologías y se debe concretar la relación causal entre los hechos y el daño, si existe. Además, entre el profesional forense y la persona evaluada, no se establece relación alguna más allá de un adecuado rapport que favorezca la colaboración y disminuya la victimización. Sin embargo, en un informe clínico, el objetivo del profesional es ayudar a superar la problemática de todo paciente que acude buscando ayuda, y para ello es necesario el establecimiento de una relación de alianza terapéutica, sin cuestionarse el origen de la sintomatología.

Por otra parte, los conocimientos de ambos profesionales son diferentes. En el caso del personal terapéutico, su conocimiento está enfocado en los tratamientos terapéuticos, en tanto que el colectivo forense estudia el estado clínico y cómo este influye en el comportamiento desde una óptica legal (Muñoz et al., 2011), por lo que ha de tener conocimientos sobre la legislación vigente para poder ilustrar a los operadores jurídicos sobre cómo la psicopatología puede afectar a las capacidades cognitivas, volitivas, a la capacidad de prestar testimonio; sobre cuestiones relacionadas con victimología (el caso que nos ocupa); y sobre la relación-causal entre los hechos y el estado psíquico derivado de un delito (huella psicológica). Es decir, no basta únicamente con el diagnóstico (Echeburúa, Muñoz y Loinaz, 2011), sino que se ha de establecer la influencia y constatar la repercusión del trastorno sobre la persona. Finalmente, en el contexto forense es de suma relevancia obtener información que no provenga exclusivamente del propio sujeto, al tiempo que se utilizan metodologías que cuenten con escalas de fiabilidad y validez; cuestiones de menor importancia en el ámbito clínico.

Además, otras características como la temporalización, a quién va destinado el informe, la confidencialidad, etc., también tienen implicaciones diferentes en función de si se trata de un informe clínico o una pericial forense. En conclusión, es importante que la judicatura y magistratura no equiparen ambos informes, ya que el valor probatorio es diametralmente opuesto.

Según el tipo de profesional que realiza los informes periciales, los datos revelan que son llevados a cabo por profesionales de la psicología en el $36 \%$ de las ocasiones; por profesionales de la medicina, en el $22 \%$; por ambos, en el $27 \%$; y el $15 \%$ restante es realizado por equipos psicosociales. Sin embargo, únicamente en 10 de las 107 sentencias aparecía reflejada la prueba psicométrica utilizada para corroborar de modo intermedidas el daño en la población evaluada. Las más utilizadas fueron el AVE (test sobre acoso y violencia escolar), en 8 sentencias; el TAMAI (test autoevaluativo multifactorial de adaptación infantil), en 1 sentencia; y el CESC (cuestionario para evaluar las relaciones entre iguales), en 1 sentencia. Aunque esto no es prueba de que las valoraciones estuvieran realizadas de manera inapropiada, la escasa alusión a una valoración multimétodo, y a la utilización 
de pruebas psicométricas robustas y con indicadores de validez bien documentados, como puede ser el MMPI-A (inventario multifásico de la personalidad Minnesota), podría explicar, en parte, algunos de los diagnósticos que no constituirían huella per se, ya que son inherentes a multitud de problemáticas, y que no pueden atribuirse inequívocamente al hecho enjuiciado.

Asimismo, cuestionarios de amplio uso como el AVE no proporcionan resultados válidos para el contexto judicial por el elevado número de falsos positivos (criterio de tolerancia cero, cualquier conducta de abuso en la escuela es clasificado como potencial acoso escolar). Además, aunque el TAMAl sí cuenta con escalas de control, es una prueba psicométrica que estudia específicamente la inadaptación en diversos ámbitos (social, familiar, escolar, etc.), pero no ofrece impresiones diagnósticas sobre trastorno alguno. Respecto a la aplicación del MMPI-A, la limitación la encontramos en la edad de la población a la que se le puede administrar, que se sitúa entre los 14 y los 18 años. Sin embargo, la psicología cuenta con una variedad de pruebas psicométricas que cumplen los requisitos que requiere el sistema judicial, como puede ser el SENA (sistema de evaluación de niños y adolescentes). Este cuestionario, que está estructurado en niveles en función de la edad, ofrece en su versión 3 la posibilidad de valorar a menores de entre 6 y 12 años, y en el nivel 4, de entre 12 y 18 años. Además, entre las múltiples escalas que incluye, una de ellas valora la posibilidad de sufrir acoso escolar. En consecuencia, solo con estos dos ejemplos (MMPI-A y SENA) podríamos tener cubierta toda la franja de edad escolar y adolescente; lo que, unido a una correcta entrevista clínico-forense, permitiría una valoración completa y robusta, con el preceptivo establecimiento de la relación causal (en caso de existir).

Las «cuantías de las indemnizaciones» solicitadas fluctúan entre los 500 y los 202.345 euros. No obstante, las compensaciones realmente concedidas oscilan entre los 120 y los 46.129 euros. Si relacionamos estas con los daños psicológicos, observamos que no existe un criterio unánime en el importe de la indemnización, ya que este puede ser similar ante un diagnóstico de trastorno por estrés postraumático (TEP) - grave y altamente incapacitante-o ante un diagnóstico de trastorno ansioso-depresivo. Asimismo, dentro de una misma categoría diagnóstica también observamos que las sumas concedidas abarcan un amplio rango (por ejemplo, indemnizaciones de $5.000 €, 10.000 €, 17.500 €, 30.000 €$ y $40.000 €$ ante el mismo diagnóstico de TEP). Variaciones similares encontramos con el resto de las patologías diagnosticadas, incluso en aquellas sintomatologías que no se llegan a concretar en una categoría concreta, como pueden ser somatizaciones (por ejemplo, obteniendo $11.200 €$ ) o inadaptación y baja autoestima (por ejemplo, $6.000 € 12.000 €$ e incluso $30.000 €$ ).

En cuanto al «contenido de las sentencias", se constata acoso en el $63,8 \%$ de las ocasiones y no se aprecia acoso en el $36,2 \%$ restante. Respecto a la actuación del centro, encontramos un $39,3 \%$ de sentencias que no se pronuncian sobre este extremo; un 20,6\% que certifica que hubo inacción del centro (culpa in vigilando), esto es, que el centro no actuó con la debida diligencia y con todos los medios a su alcance para evitar el acoso escolar; 
en un 39,3\% fallan que no se aprecia inacción del centro, es decir, que el centro actuó y puso todos los medios para evitar, corregir o superar satisfactoriamente la situación; y en un solo caso se dio la situación denominada "culpa in vigilando» limitada o parcial. Esta cuestión es de especial interés, puesto que, cuando el alumnado se encuentra en los centros de enseñanza no superior, se produce una transferencia de la «guarda» de menores al centro educativo que conlleva el deber objetivo de cuidado, control y vigilancia, incurriendo en una irresponsabilidad en caso de deficiente organización de las personas o medios que pueda ser atribuido a dicho centro. Esto significa que la denuncia o demanda por acoso se basa en el criterio denominado "culpa in vigilando". Generalmente aparece recogido en las sentencias, haciendo alusión al artículo 1.903 del Código Civil, que reza: «La obligación que impone el artículo anterior es exigible, no solo por los actos u omisiones propios, sino por los de aquellas personas de quienes se debe responder». De facto, se estipula que «los padres son responsables de los daños causados por los hijos que se encuentren bajo su guarda», pero que «las personas o entidades que sean titulares de un centro docente de enseñanza no superior responderán por los daños y perjuicios que causen sus alumnos menores de edad durante los periodos de tiempo en que los mismos se hallen bajo el control o vigilancia del profesorado del centro, desarrollando actividades escolares o extraescolares y complementarias». Concluyendo, finalmente, que «la responsabilidad de que trata este artículo cesará cuando las personas en él mencionadas prueben que emplearon toda la diligencia de un buen padre de familia para prevenir el daño».

En lo que respecta a los «fallos» dictados, el 22,4 \% conllevó únicamente un fallo penal; el 24,3\%, una indemnización; el 18,4 \%, una medida penal y una indemnización; en el 9,2 \% se produjo absolución; y el $23,5 \%$ de los recursos fue desestimado. En cuanto al contenido del fallo, los datos revelan que, en lo que respecta a las medidas adoptadas de índole penal, fueron principalmente las siguientes: libertad vigilada en el $35 \%$ de los casos; medida en medio abierto, en el $8 \%$; trabajo en beneficio de la comunidad, en el $22 \%$; medidas educativas, en el $32 \%$; y medidas ambulatorias, en un $3 \%$. Respecto al tiempo, las medidas oscilaban desde los 2 a los 21 meses. En lo tocante a las horas de beneficio a la comunidad o medidas educativas, la temporalidad se distribuía desde las 50 a las 200 horas. Como se puede observar, las medidas suelen tener un carácter reeducativo más que punitivo, siguiendo los preceptos de la Ley orgánica reguladora de la responsabilidad penal de los menores (LORPM), cuyo fin es modelar la conducta disruptiva de la infancia y adolescencia, aprovechando el estadio evolutivo en el que se encuentran, con el objetivo de enseñarles conductas prosociales que les alejen de la vía jurídica.

Como «ejemplos de acciones encaminadas a hostigar» y menoscabar la integridad física del grupo de iguales, encontramos un amplio elenco, desde insultos como «michelín», «guarra», «pelofrito», «maricón», «ojo loco», «cara de rata», «Joker» (porque tenía eccemas en la boca); a expresiones como «cuidado que el virus se contagia»; o acciones como impedirle entrar en clase diciendo que no se permitían animales, registrarle la mochila y comerse su bocadillo, obligarle a ladrar como un perro, vaciar su mochila en una papelera por no acceder a lo requerido y un sinfín de estrategias más. 


\subsection{Otras cuestiones relacionadas con los hallazgos en las sen- tencias}

Respecto al perfil de las víctimas, encontramos que las estrategias de acoso van dirigidas a todo tipo de compañeros. A veces, las víctimas son elegidas por su orientación sexual (lesbiana, gay, etc.); por ser superdotadas; por pertenecer a alguna «tribu urbana», como los Emo; por padecer algún tipo de trastorno, como puede ser la epilepsia; por pertenecer a religiones diferentes (por ejemplo, insultos como «mora»); o por cualquier otro motivo (por ejemplo, insultos como «rumano adoptado», «Tobi», para denominar a una menor con la intención de equipararla a un perro, etc.). También encontramos estrategias dirigidas a menores con diferentes grados de minusvalías (en una sentencia constaba un menor con una minusvalía del $33 \%$ y en otra con una minusvalía del $37 \%)$.

Una cuestión que llama poderosamente la atención es que, en alguna ocasión, en las resoluciones judiciales se pone de manifiesto que se duda de la credibilidad de la víctima, sin embargo, no se realiza petición de informe pericial alguno con el objetivo de someter a análisis su testimonio para ver si reúne criterios avalados por la literatura científica que están presentes en las memorias de hechos vividos y que no se encuentran en las memorias de hechos fabricados o inventados. En otra resolución, se acredita que no queda probado el recrudecimiento de la sintomatología porque el informe clínico no es suficiente. Nuevamente, se observa que no se hace uso de los medios que existen a disposición judicial, como puede ser la petición de una valoración psicológico-forense que establezca si existe nexo o no entre los hechos enjuiciados y el agravamiento, o si realmente se constata un empeoramiento respecto a una sintomatología previa o de base.

Respecto a las explicaciones que ofrecen los centros escolares ante las acusaciones de acoso en el centro y su actuación como agentes que ejercen la tutela de menores mientras permanecen en él, nos encontramos con cuestiones tan grotescas como referir que se trata de una persona peruana y que no se adapta al centro. En un caso en el que ataron a la víctima con una cuerda, la directora lo denominó "cordel», intentando quitar relevancia a la cuestión; en tanto que otra profesora recomienda directamente a los padres de un menor que es víctima de acoso que le compren un balón para que el niño pueda jugar. A nuestro entender, esto denota falta de sensibilidad con la temática y de habilidades para la resolución de problemas. A este respecto, en muy pocas ocasiones se hace referencia a la opción de una mediación. Además, también se constata que, a veces, las familias de las personas que acosan no se muestran colaboradoras, bien no reconociendo la conducta de su propia descendencia, dificultando así que esta tome conciencia del daño causado, o bien interfiriendo directamente con las medidas adoptadas en el centro educativo. 


\subsection{Conclusiones}

\subsubsection{Respecto al acoso escolar}

Niños y niñas son víctimas de acoso escolar en igual proporción (aunque se encuentren diferencias en las tácticas utilizadas), mostrándose la edad entre los 12 y los 14 años como la franja de mayor probabilidad de que ocurra. El daño psicológico que genera el acoso escolar es considerado, en la mayoría de las ocasio-

\section{El daño psicológico que genera el acoso escolar es considerado, en la mayoría de las ocasiones, como muy grave, pudiendo tener repercusión incluso a muy largo plazo} nes, como muy grave, pudiendo tener repercusión incluso a muy largo plazo. La presencia de público, así como un amplísimo porcentaje de participación en grupo para lograr el acoso, nos hace pensar que trabajar la empatía es fundamental para poder disminuir el número de agresiones.

Destaca la gran heterogeneidad de trastornos diagnosticados como consecuencia del daño producido por el acoso. Sin embargo, para que este pueda ser considerado huella psicológica en el contexto judicial, debe responder a una causalidad respecto a los hechos enjuiciados, y esto no siempre es así, dado que en ocasiones encontramos sintomatología aislada inespecífica que no constituye trastorno alguno. Es decir, es necesario mejorar la sensibilidad diagnóstica. En este sentido, también es llamativo que casi la mitad de las sentencias no hacían alusión alguna a ningún tipo de informe psicológico forense, desde nuestro punto de vista, imprescindible para poder garantizar una adecuada valoración tanto del daño producido como del estudio de la realidad de las declaraciones.

\subsubsection{Respecto a la utilización de las nuevas tecnologías en el acoso escolar}

Aunque nuestros datos advierten de la posibilidad de que las menores empleen en mayor medida el ciberacoso, encontramos que no existen diferencias de género en cuanto a las víctimas.

El desarrollo del pensamiento crítico se revela como una herramienta fundamental para que la infancia en general pueda conocer los riesgos y así prever las consecuencias a corto y largo plazo de la información, mensajes y demás cuestiones que comparte en las redes sociales, ya que una única acción de este tipo puede desembocar en un daño irreparable por su gran capacidad de difusión y alcance.

A nivel judicial, el enfoque principal que recibe la suplantación de identidad o la difusión de fotografías o información confidencial, así como otros delitos relacionados con el ciberacoso, se encuadra fundamentalmente como una cuestión de revelación de secretos. 


\subsubsection{Respecto al uso de las nuevas tecnologías por parte de la pobla- ción más joven}

Dada la falta de conciencia de riesgo que presenta esta población sobre el uso de las nuevas tecnologías, prevenir, concienciar y educar son las tres premisas fundamentales para un adecuado manejo de las mismas. Para ello, el establecimiento de las normas y de los límites respecto a la creación de una cultura positiva en relación con un uso racional de las TIC conlleva inexorablemente a que las familias se formen en la utilización de dichas tecnologías y se comprometan a acompañar a su prole en el inicio de su andadura en la vida virtual. Asimismo, es importante hacer ver a la población infantil y juvenil que no deberían llevar a cabo en la vida online ningún tipo de conducta que no realizarían en la vida real, dado que el anonimato y el sentido de invulnerabilidad que les infunde la red les lleva a exponerse a multitud de riesgos y a la comisión de actos, en ocasiones, delictivos.

\section{Señales de alarma y pautas de actuación para los proge- nitores y docentes ante el bullying y/o el ciberacoso}

\subsection{Señales de alarma}

Hay una serie de señales de alarma que pueden ayudar a padres y a docentes a detectar la existencia de un problema. Sin embargo, dichos indicadores son inespecíficos, por lo que será preciso indagar más exhaustivamente acerca de si ocurren como respuesta a una situación de bullying y/o ciberacoso, o si se producen ante cualquier otra problemática que esté afectando a nuestros vástagos o al alumnado en cuestión. Las señales a las que deberíamos prestar atención son:

- Petición para que le lleven al colegio (en el momento en que toca el timbre y no antes) y para que le recojan del colegio.

- Cambio de itinerario, ruta o costumbres a la hora de ir al centro escolar.

- Abandono de actividades placenteras o hobbies.

- Abandono del uso del móvil, de la tableta, del ordenador, etc. (alta probabilidad si se produce ciberacoso).

- Disminución del rendimiento académico o dificultad de concentración.

- Problemas somáticos: dermatológicos, insomnio, con la alimentación, dolores de cabeza, molestias gastrointestinales, náuseas, etc.

- Actitud irascible o sobresaltos continuos.

- Pérdida frecuente de material escolar o deterioro del mismo. 
No obstante, cuando se ha constatado un problema como el acoso escolar, no debemos perder de vista a quienes ejercen la agresión ni a quienes la observan, puesto que, si no se interviene también sobre ellos, el problema tiene una alta probabilidad de volver a reproducirse, produciendo unos efectos altamente perniciosos también para ellos. Así, como consecuencias para la persona que agrede, podemos destacar el desajuste personal y social, una mayor
Cuando se ha constatado un problema como el acoso escolar, no debemos perder de vista a quienes ejercen la agresión ni a quienes la observan, puesto que, si no se interviene también sobre ellos, el problema tiene una alta probabilidad de volver a reproducirse probabilidad de implicación en conductas delictivas a largo plazo y el desarrollo de una concepción instrumental de la violencia. En tanto que, para el público, se agudizan los sentimientos de culpa o impotencia, la disminución de la capacidad de empatía, se generan distorsiones respecto a su responsabilidad personal y, a largo plazo, se produce una mayor dificultad para identificar situaciones injustas (Velasco et al., 2014).

\subsection{Pautas de actuación}

Debemos partir de la idea de que al sector de menor edad le resulta muy difícil pedir ayuda en este tipo de situaciones, bien por las normas no escritas que asocian "chivarse» como algo negativo, bien porque siente vergüenza, o bien porque tiene miedo a no ser creído o a ser castigado (Aullué, Carmona, Mira y Velázquez, 2017; De Haro, 2012). Por todo ello, es importante permanecer serenos cuando se expone la situación y transmitirle comprensión, así como que está siendo escuchado, al tiempo que se le explicará que se intentará poner todos los medios de los que dispongamos para resolver el problema. Es útil hacerle partícipe de las decisiones, porque esto le devolverá cierta sensación de control. No obstante, debemos evitar hacer promesas que no se podrán cumplir, restar importancia a la cuestión, culpabilizar o promover venganza.

Asimismo, también podemos acudir al centro escolar para recibir información sobre su normativa interna, exponer nuestras sospechas sobre los hechos que están ocurriendo y solicitar la activación del protocolo sobre acoso escolar, el uso de una medida de mediación, etc. En última instancia, si no se han adoptado medidas, y la situación se mantiene, la interposición de una denuncia sería el siguiente paso.

En conclusión, estar informados sobre las distintas posibilidades de actuación, así como establecer los medios de comunicación adecuados con la población juvenil, y transmitirles la idea de que pueden contar con nuestro apoyo, ahora o cuando decidan, es el mejor modo de sentar las bases para poder atajar una situación de esta índole con la finalidad de intentar que los daños que se produzcan sean los mínimos posibles. 
Por otra parte, en la era digital en la que nos encontramos, desde muy temprana edad se tiene acceso a dispositivos con conexión a internet (por ejemplo, móvil, tableta, ordenador, etc.). Acompañar a menores y adolescentes en su vida online es una herramienta fundamental para un correcto uso de los mismos. Para ello es fundamental establecer normas a la hora de usar la tecnología y cuáles serán las consecuencias por su incumplimiento. los deberes y responsabilidades que conlleva el uso de internet (por ejemplo, todo lo que se publica deja de estar bajo nuestro control; la huella en internet es permanente; pensando a largo plazo, lo que hoy nos hace gracia puede tener consecuencias en un futuro; etc.). Del mismo modo, debemos trasmitir a menores y adolescentes la idea de que no se deben convertir en cómplices si reciben mensajes/fotos hirientes sobre su grupo de iguales, evitando la difusión de los mismos y poniéndolo

Debemos trasmitir a menores y adolescentes la idea de que no se deben convertir en cómplices si reciben mensajes/fotos hirientes sobre su grupo de iguales, evitando la difusión de los mismos y poniéndolo en conocimiento de personas adultas en conocimiento de personas adultas. De este modo se protegerán ellos y ayudarán a proteger a los demás.

También debemos hacer hincapié en la correcta utilización de contraseñas, en el conocimiento de las opciones de privacidad y, sobre todo, en el pensamiento crítico (no todo lo que aparece en la red es real).

\section{Referencias bibliográficas}

AlBuhairan, F., Abou Abbas, O., El Sayed, D., Badri, M. , Alshahri, S. y Vries, N. de. (2017). The relationship of bullying and physical violence to mental health and academic performance: a cross-sectional study among adolescents in Saudi Arabia. International Journal of Pediatrics and Adolescent Medicine, 4, 61-65.

Antila, H., Arola, R., Hakko, H., Riala, K., Riipinen, P. y Kantojärvi, L. (2017). Bullying
En la era digital en la que nos encontramos, desde muy temprana edad se tiene acceso a dispositivos con conexión a internet. Acompañar a menores y adolescentes en su vida online es una herramienta fundamental para un correcto uso de los mismos 
ción frente al acoso y el ciberacoso para padres y madres. Save the Children España.

Avilés, J. (2006). Bullying: el maltrato entre iguales: agresores, víctimas y testigos en la escuela. Salamanca: Amarú Ediciones.

Baldry, A. C. (2004). The impact of direct and indirect bullying on the mental and physical health of Italian youngsters. Aggressive Behavior, 30, 343-355.

Benedicto, J. (Dir.), Echaves, A., Jurado, T., Ramos, M. ${ }^{a}$ y Tejerina, B. (2017). Informe Juventud en España 2016. Instituto de la Juventud. Recuperado de <http://www. injuve.es/sites/default/files/2017/24/publi caciones/informe-juventud-2016.pdf> (consultado el 15 de noviembre de 2018).

Berger, K. S. (2016). Psicología del desarrollo: infancia y adolescencia. Madrid, España: Editorial Médica Panamericana.

Björkqvist, K. (2001). Different names, same issue. Social Development, 10, 272-274.

Blaya, C., Debarbieux, E., Rey Alamillo, R. del y Ortega Ruiz, R. (2006). Clima y violencia escolar. Un estudio comparativo entre España y Francia. Revista de Educación, 339, 293-315.

Brewer, G. y Kerslake, J. (2015). Cyberbullying, self-esteem, empathy and Ioneliness. Computers in Human Behavior, 48, 255-260.

Calmaestra, J., Ortega, R. y Mora-Merchán, J. A. (2008). Las TIC y la convivencia. Un estudio sobre formas de acoso en el ciberespacio. Investigación en la Escuela, 64, 93-103.

Cánovas, G., García de Pablo, A., Oliaga San Atilano, A. y Aboy Ferrer (2014). Menores de edad y conectividad móvil en España: tablets y smartphones. España: Centro de Seguridad en Internet para los Menores en España: PROTEGELES. Recuperado de <https://kidsandteensonline.files. wordpress.com/2014/07/estudio_movil_ smartphones_tablets_protegeles.pdf> (consultado el 11 de enero de 2019).

Castilla, C. y Vicente, A. (2018). Las redes sociales son un factor de riesgo para la autoestima de los más jóvenes. Infocop, 81, 20.

Consellería de Cultura, Educación e Ordenación Universitaria. (2015). Prevención, detección e tratamento do acoso escolar e ciberacoso. Santiago de Compostela, España.

D’Angelo, L. A. y Fernández, D. R. (2011). Clima, conflictos y violencia en la escuela. Buenos Aires, Argentina: United Nations International Children's Emergency Fund (UNICEF).

Defensor del Pueblo. (2007). Violencia escolar: el maltrato entre iguales en la educación secundaria obligatoria. Madrid, España.

DeLay, D., Zhang, L., Hanish, L. D., Miller, C. F., Fabes, R. A., Martin, C. L. y Updegraff, K. A. (2016). Peer influence on academic performance: a social network analysis of social-emotional intervention effects. Prevention Science, 17(8), 903-913.

Díaz-Aguado, M. a J., Arias, R. y Babarro, J. (2010). Estudio estatal sobre la convivencia escolar en la educación secundaria obligatoria. Ministerio de Educación.

Dobarro, A. (2011). Revisión de los principales estudios sobre la incidencia de la violencia escolar en Asturias. Magister: Revista Miscelánea de Investigación, 24, 77-89.

Eastman, M., Foshee, V., Ennett, S., SotresÁlvarez, D., Reyes, H. L. M., Faris, R. y North, K. (2018). Profiles of internalizing and externalizing symptoms associated with bullying victimization. Journal of Adolescence, 65, 101-110.

Echeburúa, E., Muñoz, J. M. y Loinaz, I. (2011). La evaluación psicológica forense 
frente a la evaluación clínica: propuestas y retos de futuro. International Journal of Clinical and Health Psychology, 11, 141-159.

Evans-Lacko, S., Takizawa, R., Brimblecombe, N., King, D., Knapp, M., Maughan, B. y Arseneault, L. (2017). Childhood bullying victimization is associated with use of mental health services over five decades: a longitudinal nationally representative cohort study. Psychological Medicine, 47(1), 127-135.

Fuertes, J. A., Martínez, J. L. y Hernández, A. (2001). Relaciones de amistad y competencia en las relaciones con los iguales en la adolescencia. Revista de Psicología General y Aplicada: Revista de la Federación Española de Asociaciones de Psicología, 54(3), 531-546.

Gini, G., Card, N. A. y Pozzoli, T. (2018). A meta-analysis of the differential relations of traditional and cyber-victimization with internalizing problems. Aggressive Behavior, 44(2), 185-198.

Griffin, R. S. y Gross, A. M. (2004). Childhood bullying: current empirical findings and future directions for research. Aggression and Violent Behavior, 9(4), 379-400.

Gualdo, A., Arnaiz, P. y Maquillón, J. J. (2014). Acceso a las tecnologías, rendimiento académico y cyberbullying en escolares de secundaria. Revista Iberoamericana de Psicología y Salud, 5, 119-133.

Haro, P. J. de. (2012). En clase me rechazan. Me amenazan en el instituto. La familia ante momentos difíciles (pp. 53-58). Comunidad de Madrid. Dirección General de Familia.

Hoffman, C. Y., Phillips, M. D., Daigle, L. E. y Turner, M. G. (2017). Adult consequences of bully victimization: are children or adolescents more vulnerable to the victimization experience? Youth Violence and Juvenile Justice, 15(4), 441-464.
Howard, A. M., Landau, S. y Pryor, J. B. (2014). Peer bystanders to bullying: who wants to play with the victim? Journal of Abnormal Child Psychology, 42(2), 265-276.

Juvonen, J. y Galván, A. (2008). Peer influence in involuntary social groups: lessons from research on bullying. En M. Prinstein y K. Dodge, Understanding Peer Influence in Children and Adolescents (pp. 225-244). Nueva York, NY: Guilford Press.

Kaltiala-Heino, R., Rimpelä, M., Rantanen, P. y Rimpelä, A. (2000). Bullying at school-an indicator of adolescents at risk for mental disorders. Journal of Adolescence, 23(6), 661-674.

Kärnä, A., Voeten, M., Poskiparta, E. y Salmivalli, C. (2010). Vulnerable children in varying classroom contexts: bystanders' behaviors moderate the effects of risk factors on victimization. Merrill-Palmer Quarterly, 56(3), 261-282.

Kärnä, A., Voeten, M., Little, T. D., Poskiparta, E., Kaljonen, A. y Salmivalli, C. (2011). A largescale evaluation of the KiVa antibullying program: grades 4-6. Child Development, 82(1), 311-330.

Kim-Cohen, J., Caspi, A., Taylor, A., Williams, B., Newcombe, R., Craig, I. W. y Moffitt, T. E. (2006). MAOA, maltreatment, and gene-environment interaction predicting children's mental health: new evidence and a meta-analysis. Molecular Psychiatry, 11(10), 903-913.

Kowalski, R., Limber, S. y Agatston, P. (2010). Cyber Bullying: el acoso escolar en la er@ digit@I. Bilbao: Desclée de Brower.

Livingstone, S., Haddon, L., Görzig, A. y Ólafsson, K. (2011). Risks and safety on the internet: the perspective of european children. Full findings. Londres: LSE, EU Kids Online. Recuperado de <http://eprints.Ise. ac.uk/33731/1/Risks\%20and\%20safe ty $\% 20$ on\%20the\%20internet $\% 28$ Ise 
ro\%29.pdf> (consultado el 21 de noviembre de 2018).

Martín, J. A. F., Álvarez, J. L. M. y Hernández, A. (2001). Relaciones de amistad y competencia en las relaciones con los iguales en la adolescencia. Revista de Psicología General y Aplicada: Revista de la Federación Española de Asociaciones de Psicología, 54(3), 531-546.

Martínez, B. (2014). El mundo social del adolescente: amistades y pareja. En E. Estévez (Ed.), Los problemas en la adolescencia: respuestas y sugerencias para padres y educadores. Madrid, España: Síntesis.

Martos, A. y Rey, R. del. (2013). Implicación del alumnado con necesidades específicas de apoyo educativo en bullying. Apuntes de Psicología, 31(2), 183-190.

Megías, I. y Rodríguez, E. (2014). Jóvenes y comunicación: la impronta de lo virtual. Madrid, España: Centro Reina Sofía sobre Adolescencia y Juventud.

Muñoz, J. M., Manzanero, A. L., Alcázar, M. Á., González, J. L., Pérez, M. ${ }^{a}$ L. y Yela, M. ${ }^{a}$ (2011). Psicología jurídica en España: delimitación conceptual, campos de investigación e intervención y propuesta formativa dentro de la enseñanza oficial. Anuario de Psicología Jurídica, 21, 3-14.

Nielsen, M. B., Tangen, T., Idsoe, T., Matthiesen, S. B. y Magerøy, N. (2015). Post-traumatic stress disorder as a consequence of bullying at work and at school. A literature review and meta-analysis. Aggression and Violent Behavior, 21, 17-24.

Ochaita, E., Espinosa, M. ${ }^{a}$ Á. y Gutiérrez, H. (2011). Las necesidades adolescentes y las nuevas tecnologías de la información y la comunicación. Revista de Estudios de Juventud, 92, 87-110.

Olweus, D. (1983). Low school achievement and aggressive behavior in adolescent boys. En D. Magnusson y V. Allen (Eds.), Human development: an interactional perspective (pp. 353-365). Nueva York, NY: Academic Press.
Olweus, D. (1998). Conducta de acoso de amenaza entre escolares. Madrid: Morata.

Olweus, D. y Limber, S. P. (2010). Bullying in school: evaluation and dissemination of the Olweus Bullying Prevention Program. American Journal of Orthopsychiatry, 80(1), 124.

Ovejero, A. (2013). El acoso escolar: cuatro décadas de investigación internacional. En A. Ovejero, P. K. Smith y S. Yubero (Eds.), El acoso escolar y su prevención: perspectivas internacionales (pp. 11-57). Madrid: Biblioteca Nueva.

Pellegrini, A. D. y Smith, P. K. (1998). The development of play during childhood: forms and possible functions. Child Psychology and Psychiatry Review, 3(2), 51-57.

Reijntjes, A., Kamphuis, J. H., Prinzie, P. y Telch, M. J. (2010). Peer victimization and internalizing problems in children: a meta-analysis of longitudinal studies. Child Abuse and Neglect, 34, 244-252.

Reijntjes, A., Vermande, M., Thomaes, S., Goossens, F., Olthof, T., Aleva, L. y Meulen, M. van der. (2016). Narcissism, bullying, and social dominance in youth: a longitudinal analysis. Journal of Abnormal Child Psychology, 44(1), 63-74.

Rigby, K. (2002). New perspectives on bullying. Londres: Jessica Kingsley.

Roa, C., Álvarez, S., Arévalo, L., Barón, E., Larrota, D. y Rairán, V. (2012). Prevalencia de conducta delictiva como una consecuencia a largo plazo en personas que han sido actores de intimidación escolar. Contextos, 8, 1-18.

Rodicio-García, M. ${ }^{a}$ L. elglesias-Cortizas, M. ${ }^{a}$ J. (2011). El acoso escolar: diagnóstico y prevención. Biblioteca Nueva.

Salmivalli, C. (2014). Participant roles in bullying: how can peer bystanders be utilized in interventions? Theory Into Practice, 53(4), 286-292.

Salmivalli, C., Sainio, M. y Hodges, E. V. (2013). Electronic victimization: correlates, 
antecedents, and consequences among elementary and middle school students. Journal of Clinical Child \& Adolescent Psychology, 42(4), 442-453.

Sastre, A. (Coord.). (2016). Yo a eso no juego: bullying y ciberbullying en la infancia. Save the Children.

Slee, P. T. (1995). Bullying in the playground: the impact of inter-personal violence on Australian children's perceptions of their play environment. Children's Environments, 12(3), 320-327.

Smith, P. K., Smees, R. y Pellegrini, A. D. (2004). Play fighting and real fighting: using video playback methodology with young children. Aggressive Behavior: Official Journal of the International Society for Research on Aggression, 30(2), 164-173.

Soto, A., Miguel, N. de y Díaz, V. P. (2018). Abordaje de adicciones a nuevas tecnologías: una propuesta de prevención en contexto escolar y tratamiento de rehabilitación. Papeles del Psicólogo, 39(2), 120-126.
Stein, J. A., Dukes, R. L. y Warren, J. I. (2007). Adolescent male bullies, victims, and bully: a comparison of psychosocial and behavioural characteristics. Journal of Pediatric Psychology, 32(3), 273-282.

Thornberg, R. (2012). Informed grounded theory. Scandinavian Journal of Educational Research, 56(3), 243-259.

Thornberg, R. y Jungert, T. (2013). Bystander behavior in bullying situations: Basic moral sensitivity, moral disengagement and defender self-efficacy. Journal of Adolescence, 36(3), 475-483.

Velasco, J., Quinteiro, I., Monteserín, R., Arias, E., Carracedo, S. y González, B. (2014). Bule contra el bullying: cómo prevenir el acoso escolar. Campus Na Nube.

Zych, I., Ortega, R. y Rey, R. del. (2015). Systematic review of theoretical studies on bullying and cyberbullying: facts, knowledge, prevention, and intervention. Aggression and Violent Behavior, 23, 1-21.

\section{Máster en Formación del Profesorado de Educación Secundaria}

Este máster oficial en Formación del Profesorado de Educación Secundaria Obligatoria, Bachillerato, Formación Profesional y Enseñanza de Idiomas [60 créditos ECTS] tiene una duración normal de 12 meses.

Dirigido a: La universalización de la enseñanza secundaria y el incremento de la atención a la diversidad de alumnos en todos los niveles de enseñanza han hecho más patente la necesidad de mayor formación didáctica. El educador ya no solo ha de ser un experto en su materia, sino que debe tener la suficiente capacidad didáctica para adaptar la misma a grupos de alumnos muy heterogéneos en intereses, capacidades y actitudes.

Objetivos: Adquirir todas las habilidades y competencias necesarias para poder desarrollar una carrera profesional en el ámbito de la enseñanza en los niveles de Educación Secundaria Obligatoria y Bachillerato, Formación Profesional y Enseñanzas de Idiomas de acuerdo a la normativa vigente, ya sea para dar clase en centros públicos, privados o concertados. Ofrecer formación integral y especializada a los participantes. 